\title{
Work placements in doctoral research training in the humanities: Eight cases from Translation Studies
}

Anthony Pym, Gabriel González Núñez, Marta Miquel-Iriarte, Sara Ramos Pinto, Carlos S. C. Teixeira, Wine Tesseur*

Abstract: Research cooperation between academic and nonacademic institutions tends not to concern the humanities, where mutual financial rewards are mostly not in evidence. The study of eight nonacademic placements of doctoral researchers working on interlingual translation nevertheless indicates some degree of success. It is found that the placements lead to ongoing cooperation when the following conditions are met: 1) the nature of the placement is understood and relations of trust are established; 2) mutual benefits are envisaged; and 3 ) there are prior arrangements for receiving visiting researchers. A placement can nevertheless be successful when one of the last two factors is missing. Further, the measure of success for placements in the humanities should concern social and symbolic benefits, in addition to financial profits.

Key words: Industry-university collaboration; PhD research; Translation Studies; nonacademic partnership

\section{Introduction}

The 2000 Lisbon Strategy aimed to make the European Union "the most competitive and dynamic knowledge-based economy in the world" by 2010 (European Council 2000). The general failure of the strategy is now widely recognized, and one of the reasons for the failure is attributed to relations between universities and industry. In order to ensure innovation in a knowledge-based economy, it is considered essential that academic and nonacademic partners cooperate in research projects at various levels. Doctoral research is obviously a key component of most such projections.

Recent studies of university-industry collaboration (e.g. Borrell-Damian 2009, Pertuzé et al. 2010, Todd et al. 2011, Technopolis 2011, Science Business Innovation Board 2012, Lind et al. 2013) nevertheless paint a dappled picture, with the headlined success stories being written against a background of inconclusive attempts:

Universities and other higher education institutions (HEIs) can and do make a significant contribution to regional economic and social development, a role growing in importance in a globalised economy. Too often, however, the potential for synergy is thwarted by failures of communication between regional stakeholders and HEIs, weak or unclear policy signals, and conflicting agendas in institutions. (Technopolis 2011: 12)

\footnotetext{
* Paper written with reference to the project Translation Research Training: An integrated and intersectoral model for Europe (TIME- ITN 2010- 263954). EU Seventh Framework Marie Curie Initial Training Networks (ITN). 20112014.
} 
The available studies are moreover written with an eye to economic sectors where the impact of research is clear: computer science, engineering, chemistry, or medicine. These are areas where companies see advantages in setting up joint research projects or financing specific $\mathrm{PhD}$ candidates with a view to patents, which are among the arrangements most likely to lead to mutual benefits in a financial sense.

Here we report on eight attempts at cooperation in a slightly different sector. Although university research on translation between languages (here limited to written and audiovisual translation) does have a relation with the language industry, translation is obviously of interest to several other sectors as well, particularly intergovernmental and non-governmental organizations (NGOs). The potential for cooperation is not only with "industry" in the sense of private, profit-oriented companies, but also with a range of institutions that are best described as "nonacademic". Here we will be talking about "academic-nonacademic cooperation", despite an extensive literature that prefers the pair "industry-university".

Research on translation is of interest because it has largely been developed in relation with the university training of translators; it does not have a developed history of impacting on that industry in any more direct way. The main innovations in recent years (translation memories, statistical machine translation, collaborative translation software, accessible subtitling software) have mostly come from industry, rarely from a university setting. Particularly in situations where, as in our case studies here, translation research is housed in humanities departments (rather than engineering or computer science, for example), the only substantial exchange with nonacademic partners had been through work placements for trainee translators.

The TIME project set out to change this pattern. Initiated in 2011, it was a Marie Curie Initial Training Network whose full name is Translation Research Training: An integrated and intersectoral model for Europe (TIME- ITN 2010- 263954). The initial goals included:

- To increase the involvement of private/public institutions in research training in Translation Studies by kick-starting joint research training, which will lead to sustainable cooperation;

- To raise awareness of the industry of the scope and relevance of translation research and, in turn, raise awareness within academia of the needs of private and public institutions;

- To establish the foundations for academic/private sector joint $\mathrm{PhD}$ training and a joint doctoral degree. (TIME 2011)

The kind of cooperation sought here was at the level of components in the researchers' training, rather than a concrete project or a particular PhD dissertation. ${ }^{1}$ Four

\footnotetext{
${ }^{1}$ Lind et al. (2013) identify four broad forms of collaboration: distanced, translational, specified and developed. The experiences reported on here seem not to find a comfortable place in any of these categories. If the TIME project's aims fit in anywhere, it would be in the "translational" category, at least in its goals, since this is where industry and academia share the same topic, even though they have two different modi operandi. The academic partners do research in order to publish and develop knowledge. The non-academic partners aim to improve their products or their firm. The research processes try to suit both needs. However, the project's aims, as expressed above, are at best vague about what benefits the nonacademic partners are expected to gain.
} 
doctoral students and one postdoctoral researcher were each required to spend about six months in one or two work places, which included private companies, non-profit research organizations, and NGOs (all of which will here be called "host organizations"). All the organizations that initially signed up as partners in the project were significantly engaged in translation in some way, as either producers or consumers of translations. In addition to developing the communication avenues and models listed in the aims, the placements ("internships" in the United States, "secondments" in EU parlance) were supposed to enhance the researchers' training in applied research design, communication, transfer skills and general employability, and in some cases to help in the data-gathering for the researcher's doctoral dissertation. In exchange for this, the host organizations could have their costs reimbursed for up to 600 euros per month per researcher, and in some cases they received additional services such as translations, proofreading, data processing, and some initial research findings.

Together, these two aspects (research within the humanities, and a focus on training) made this project both highly innovative and extremely difficult. The aim was indeed to "kick-start" a process where previously there had been almost none. The type of cooperation being sought was essentially without a well-established model; it seems not to have been studied to any extent in previous research (although Borrell-Damian 2009 usefully stresses the doctoral candidate as a "link between university and industry"). In short, it was an adventure into relatively unchartered terrain.

Here we present each of the eight cases. The accounts are written from the perspective of the researchers themselves (the doctoral candidates and the post-doctoral researcher), with revisions and notes from a research supervisor and several representatives of the host institutions.

Since the overall project was divided into four subprojects, we retain that division here. Each subproject had one researcher (doctoral candidate) and one or two placements. Subproject 2 had a post-doctoral fellow as a second researcher.

\section{Case studies}

\section{Subproject 1: Translation technologies: for a humanization of efficiencies and usability}

This subproject required contacts with the localization industry. The researcher, a Brazilian who was based in Tarragona, Spain, had extensive experience working as a translator for major companies in several countries and was a competent user of the current translation technologies. His education background was in both Electrical Engineering and Linguistics, with a research Masters in Translation and Intercultural Studies. He was fluent in Portuguese, English, Spanish, French, and Catalan. His project was on how translators process metadata (information on translation suggestions) when using translation memories and machine translation, and his experiment involved eyetracking the on-screen performances of ten professional translators. The results of the research are potentially important for enhancing translator productivity, improving the design of translation technology, and ensuring job satisfaction among translators.

Given the researcher's experience and the industry implications of the project, it was initially assumed that the placements would be easy to organize. Further encouragement came when a long-standing contact at one of the world's largest 
multinational translation companies indicated that there was no shortage of issues they would like to see more research on, and he himself was pleased to be an industry consultant for the TIME project. Other initial contacts with a medium-sized translation company in Barcelona were also promising at first, especially since a senior project manager at the company was completing her doctoral dissertation within the same group as the researcher. The Barcelona company also signed up to be a partner in the project. In short, these looked like marriages made in heaven.

In practice, the placements were extremely difficult to organize. The initial contact person within the multinational was based in the Netherlands; he referred us to their Madrid branch, which worked with the researcher's languages. Those negotiations then fell through entirely, ostensibly because of issues of confidentiality but also because there was no prior relationship with the people there, and thus no basis for trust. The Human Resources Manager in Madrid was familiar with placements for young translators but she appeared to have no model for a visiting researcher. Would he be there to translate? If so, the company's documents belong to their clients and could not be used in public research (confidentiality is indeed a key issue in the industry). And if not, what would be the benefit for the company? Emails were sent, then resent, then not replied to; the conversations returned to previous points of departure; negotiations led nowhere.

Something similar happened with the Barcelona company. The idea of a translator coming onsite to conduct research was never clearly understood. This led to strangely circular conversations of the kind:

Company: "What do you want to do?"

Researcher: "That depends on what you want me to do." Company: "That depends on what you can do."

Researcher: "But that depends on what I am able to do at your company."

And so on, in a context where clarity of purpose is a premium asset. Although there was another doctoral researcher already within the company, the manager had a background in business rather than languages and could not see how they could benefit from such a partnership. His main concern was that the hours spent tutoring the visiting researcher would not be covered by the official allocation of 600 euros a month. At the same time, though, the company was in the throes of a merger, and their main concerns were logically with other issues.

Two further companies eventually were located, with happier stories to tell.

\section{Case Study A: MSS, Barcelona, Spain}

MSS is a small translation company with one office and is also located in Barcelona. It has 15 in-house employees plus a network of freelancers. Its major client is IBM, for whom the researcher had worked in the past. The researcher had actually known two key staff in the company for more than ten years. The company's main prior experience was with work placements for translation students: they have a permanent work-placement arrangement with one of the universities in Barcelona, and all their translators in recent years have come from that arrangement. They were nevertheless happy to have the researcher come on-site and run experiments with their translators. Given the small size 
of the company, the researcher was able to interact with staff at all levels, from the owner to the translators.

The placement lasted for four months in 2012. It enabled the researcher to gain access to professional translators who could participate as subjects in his experiment. Additionally, the researcher was able to learn about the company's internal workflow, particularly with respect to the use of translation tools and machine translation. The researcher had no need to engage in translating or other tasks that were outside the frame of his own research. The company was not carrying out any research of its own and was thus not in a position to offer any specific training in research techniques. Confidentiality was not an issue for this company, which came as something of a surprise after the previous unsuccessful negotiations.

The main costs of the placement were negligible in terms of office space and materials: the researcher brought a computer and an eye tracker to spaces assigned to people who worked from home most of the time or were on leave or vacation. There were nevertheless real costs in terms of time, since the researcher spent three to four hours with each of the ten participant translators, conducted interviews of 30 to 60 minutes with around 10 people and had two reviewers assess the translations for quality. Further, the Production and Vendor Manager and the Project Manager and Technical Support spent several hours providing him with information or direct support. These expenses might have been covered by the 600 euros per month paid to the company.

The researcher felt very well received. People in the company understood the project and the researcher was able to learn about the company through meetings and one-on-one contacts.

The main benefits to the researcher were not particularly in terms of any new knowledge about translation, since he had ample prior experience of the translation industry. However, there were insights into aspects such as how the company recruits and ranks freelance translators.

As for the company, it was aware it needed data on the increased productivity obtained with machine translation and post-editing processes. It is nevertheless doubtful that MSS actually solved any problems directly from the researcher's project, although some employees reportedly used the exchange to think about improvements to their workflows. On the other hand, the company gained prestige with its main client IBM, which saw that MSS was associated with the project and was thus interested in improving the tools and workflows related to the services they sell to IBM. This gain in status in the eyes of their major client was of considerable commercial value to MSS.

Not by chance, the placement allowed an exchange directly between the researcher and IBM, which actually occurred during the placement at MSS. IBM had been collecting data on the way its translators used translation memories and machine translation, so it was interested in what the researcher was discovering. At the same time, the researcher has remained in touch with MSS directly and will go back to them to give a seminar on his main research findings. The owner of MSS also contacted the researcher when he was looking for someone to help them with their machine-translation processes.

The researcher enjoyed carrying out the practical tasks of his research, in contradistinction to his more abstract concerns in the university setting. The staff at the company appear to have been happy to talk about what they were doing in their daily 
jobs. They were curious about the eye tracker and they seemed to feel privileged for having been "chosen" to host a European research project.

\section{Case Study B: Symantec, Dublin, Ireland}

The second placement was quite different. Symantec is a large multinational software manufacturer and security services provider, with over 18500 employees in more than 50 countries. The placement was arranged through the head of a research department in Symantec's Dublin office, although it had to be approved by the head office in California. Symantec Ireland was used to cooperating with Irish universities and hosting doctoral researchers, mainly through the Centre for Next Generation Localisation (since renamed the Centre for Global Intelligent Content), a university-industry research framework subsidized by the Irish government. Our initial contact person was actually met by the TIME supervisors at a seminar on relations between industry and the training of translators, organized by the Directorate General for Translation in Brussels. The placement thus came about as a result of at least two prior networks dealing with relations between academic and nonacademic institutions.

The placement was for two months in 2013 and was with Symantec's Language Solutions Group. This department had no direct connection with the researcher's specific project, and the main research carried out by Symantec - on developing machine translation engines and studying community collaboration-was done in a different department. It thus took some time to identify a project where the researcher could be of use, and he finished up working on a product-testing project that was not directly related to his own research interests. The main intellectual aim was nevertheless to learn about how a large software company handles terminology and carries out its own research. The researcher did not feel that the company's research was being concealed from him at all, although he never sought to ask for details that went beyond what was offered for general distribution. Confidentiality never became a real issue, since there was no conflict between what the researcher needed to know and what the company was willing to reveal, including information about some of their business practices and service providers.

The costs of the placement to the company were not significant in terms of workspace and contact hours. Indeed, the company was benefiting from free labor that it was being paid to use. The general reception in the company was very positive, and there was some interest in the researcher's project. There are plans to follow up the placement with a survey of post-editor satisfaction, which is a topic of interest to both the researcher and the company. The prestige accruing from the placement is considered of real value for future job searches.

\section{Subproject 2: Multimedia and Multimodal translation: accessibility and reception}

This subproject investigated the psycholinguistic mechanisms underlying the reading of subtitles in films. This subproject had two researchers. The doctoral fellow had a research Masters in Translation and Interpreting and a professional Masters in Audiovisual Translation; she was fluent in Spanish, English and Catalan. Her project was on how people watch films with subtitling for the deaf and hard of hearing. 
The post-doctoral fellow had a PhD in Translation Studies, was fluent in English and Portuguese, and had experience as a freelance translator. Her project was on the impact on viewers of specific variables such as speed of subtitles, source language, word frequency, recreation of linguistic variation and the inclusion of additional information on screen. The research in this subproject produces empirical data on the impact of previously untested subtitling practices and strategies.

The doctoral fellow first contacted some international translation companies but the contacts did not come to fruition, mainly due to confidentiality issues and the difficulties in envisaging a balance between professional work and research. Similarly, contacts with international associations for the deaf did not lead to any actual agreement, in part because, as associations, they had no physical workplace or organizational structure suited to the giving of formal guidance. The search thus eventually led to a small/medium sized private company, MultiSignes.

The post-doctoral fellow contacted one of the main audiovisual companies in Portugal, Sintagma Traduções. This small/medium sized private company welcomed the proposed collaboration and no further contacts were made.

\section{Case Study C: MultiSignes, Banyoles, Spain}

MultiSignes, located north of Barcelona in Spain, provides complete services for audiovisual production, including live and pre-recorded subtitling for the deaf and hard of hearing, adaptations into different sign languages, and audio description for the blind and visually impaired. They also train sign-language teachers and interpreters and coordinate the development and implementation of access services for local, national and international productions. Further, they provide postproduction services for TV, DVD and Blu-ray discs, theater, music events, conferences, and conventions.

The researcher's initial placement with the company ran for four months in 2012 and was with the subtitling department. Following this, a second four-month placement was organized in 2013 so that the researcher could work on her own experiment. Her research compares the reception processes of deaf, hard of hearing, and hearing viewers when watching films with subtitles for the deaf and hard of hearing.

The placement was expected to develop non-academic skills and to strengthen links between research and the deaf and hard of hearing community. The initial plan was for the researcher to observe how the company functioned, do some subtitling and administrative work if necessary, and write a report about the speed of live subtitles produced for TV programs. The company provides live subtitles through respeaking for TV shows such as debates or interviews and asked the researcher for a written report on how the live subtitles could be improved, with the idea of submitting the report to their TV industry partners. However, when the second experimental stage started to take shape, it was finally agreed that the report would specifically deal with the results and conclusions of the researcher's study.

Specific aims were nevertheless difficult to establish, since neither party had any real experience with this kind of cooperation. Several meetings and conversations were necessary before a work plan could be agreed upon. 
The first four months were spent in the subtitling department, which employs some eight people. The researcher initially worked with the subtitlers in pairs or groups of three: they provided information on their work, the company's subtitling style guide, and the subtitling software. The researcher visited the company two or three times a week during this period. She then did some individual translation work, which was coordinated online.

For the second four months, the researcher carried out her experiment with assistance from the coordinator of the interpreting department. The data were gathered on the premises of the company: an eye-tracker laboratory was set up in one room and interviews were conducted in another. The interpreting coordinator actually contacted participants for the study and provided sign interpreting for the tests. The number of weekly visits depended on the schedules of the interpreter and the participants (53 participants in total). There were also constant meetings with the management department.

Although the company had no prior experience with this kind of placement, it had worked with local and national institutions in projects related to accessibility. It had also participated as an industry partner in conferences in Catalonia. The staff were not able to provide any formal research training as such, but their proximity to the deaf community enabled them to give useful feedback on the researcher's questionnaires and selection of films. Confidentiality was not an issue for the company, since the researcher's project did not overlap with any of their own business.

The costs of the placement are difficult to estimate. The researcher was assigned a desk and a computer for the first four months, and used two rooms for the second period. She had regular meetings with the staff and received individual training in the subtitling software. Further, the coordinator of the interpreting department spent considerable time contacting the experiment participants, tracking their travel reimbursements, and providing sign interpreting during the 30 hours or so of the tests. The company also covered part of the cost of printing the questionnaires. For all of this time, assistance and space, they received 2,400 euros. Needless to say, their real costs were not covered.

So why should a company help research in this way? In this case, the company is young and dynamic; they had an open attitude and were willing to cooperate; communication with them was easy and fruitful. The research project was explained to the management in private meetings, and the rest of the staff knew about it in one-on-one meetings and in small-group discussions. The subtitlers were especially aware of the relevance of the research and were curious about the eye-tracking methods involved. In general, the company was interested in academic work, and this project enabled them to participate for the first time in a network on the European level. They understood that research could help them quantify the importance of accessibility, and thus help sell their products to their clients.

The benefits for the company were not only in the data generated by the researcher, but also in the prestige of being associated with a European project. When the company later applied to subtitle part of the programming of Spanish national TV, they listed their participation in this European project as one of their distinguishing factors. They were awarded the contract and have consequently expanded their team.

The benefits were also clear for the researcher. The first part of the placement enabled her to learn about audiovisual translation from the industry perspective. The placement 
also enabled her to identify connections between her research and professional practice and guidelines, as well as establish contacts with the deaf community. The researcher's enhanced contacts with the private sector should widen her possibilities for employment outside the university system, although it is also added value for her employability within the university system.

In this case, the researcher's interaction with the company extended beyond the formal placement. The company offered to distribute the final research report to all the institutions for which it provides services, and this network was then picked up by the Catalan College for Graphic Design, which further helped design the report and distribute it to the industry. This network clearly has the potential to grow.

\section{Case Study D: Sintagma Traduções, Oeiras, Portugal}

Sintagma Traduções is a company specializing in audiovisual translation, located in Oeiras (west of Lisbon) in Portugal. It employs five in-house translators but works with many more freelance translators. Besides audiovisual translation, the company also provides technical and literary translation services, conference and community interpreting, and certified subtitling courses. Building on its long tradition of organizing internships for young translators, the company was very open to adapt that model to a research placement, which lasted for three months in 2013.

The placement was expected to develop non-academic skills, strengthen the link between research and the translators' community in Portugal, and give the researcher better insight into how things happen in a professional context. The relatively small size of the company allowed the researcher to interact with staff and shadow several of them at different levels, from the director of the company to project managers and freelance translators. The researcher learned about the company's internal workflow and gained first-hand insight into the daily challenges, technical difficulties and client demands faced by translators and project managers. Confidentiality was never a problem.

The staff were not able to provide any formal research training as such, but the fact that it is one of the first and most experienced audiovisual translation companies in Portugal enabled them to provide valuable information on the history of subtitling practices in Portugal, the areas in which more empirical data is needed, and the differences between different clients' briefings. The friendly environment and genuine interest in the research made it possible for the researcher to conduct several interviews and organize a questionnaire on current subtitling practices, in which several of the professional translators participated. This provided the researcher with vital information for a future questionnaire on subtitling practices as it allowed for a much more detailed picture of the professional audiovisual translation world, the skills required and, consequently, the need for audiovisual translation training. Such contextual information also turned out to be relevant during the analysis of the empirical data collected by eyetracking and questionnaire. Additionally, the researcher was given the opportunity to complete the certification in audiovisual translation provided by the company. The prestige of the company and the possibility of formal certification were considered of real value for future job searches.

The benefits for the researcher were thus very clear, but what were the advantages for the company? Their initial involvement in this placement came from an interest in 
research itself, even if there was no financial profit involved. However, three areas were later identified to be of benefit for the company: a) the opportunity to update their translators on the latest research in audiovisual translation, b) access to empirical data regarding some of the challenges subtitlers face on a daily basis, and c) development of analytical models to help translators make faster and better informed decisions. The project managers and translators learned about eye-tracking methodology and participated in informal knowledge-exchange meetings in which the latest research in audiovisual translation was discussed. The initial results of the research project were commented on at length and research reports will be produced presenting the data in a more "user-friendly format" for translators. First versions of the models of analysis have been developed and the testing phase will be initiated in the near future. Intangible benefits for the company also ensue from the prestige of association with a European project, which allows the company to advertise its research-led services.

The main costs of the placement were the time spent with translators, use of a computer with subtitling and video editing software, and reviewing of the researcher's translation work. The company estimated the expenses to be below the 1,800 euros paid for the three-month placement.

This placement offered the researcher networking possibilities not only with this company and its translators, but also with a myriad of freelance translators and two other companies that occasionally work with Sintagma Traduções on larger projects. The researcher has remained in contact with the company and future projects are planned, namely the organization of formal knowledge-exchange seminars and a large survey of subtitling practices. Future reception studies are also being planned and Sintagma Traduções has offered to provide audiovisual material for use in the experiment.

\section{Subproject 3: Translating for minorities: linguistic diversity and integration in Europe}

This subproject concerned institutional translation policies. The researcher was a bilingual English-Spanish speaker with a degree in law and practical experience as an immigration lawyer and court interpreter in the United States. Prior to the placements, he had completed a research Masters in Translation and Intercultural Studies. His doctoral project was on translation policies in the various administrative levels of the United Kingdom.

In this case, placements were initially sought at institutions engaged in translation policies or potentially concerned with the relation between such policies and language rights. Initial contacts were made with the European Social Observatory (OSE) and a human rights NGO. While the placement with the OSE came to fruition, it became clear that the human rights NGO did not deal with language rights as such. Contacts were then unsuccessfully sought at Europe's largest international organization. Contacts were additionally sought with the Organization for Security and Co-operation in Europe's High Commissioner on National Minorities, which brought mixed results - the office of legal counsel provided some helpful feedback on the research, but they ultimately did not see how this project would fit in with their concerns. Eventually a placement was secured with the European Centre for Minority Issues (ECMI). 


\section{Case Study E: European Social Observatory (OSE), Brussels, Belgium}

The European Social Observatory (OSE) is an institution engaged in research and advocacy related to the EU's social policy. They have a team of nine employees plus three regular contributors. They focus on issues such as healthcare, mobility, labor, poverty and welfare systems.

OSE themselves first approached KU Leuven (Katholieke Universiteit Leuven), Belgium, looking for student translators who wanted a work placement. They signed on to the TIME project thinking that they were getting intern translators, but it became apparent to them early on that the placements concerned research rather than students doing translations for free.

The researcher spent three months with them in 2012. He was not assigned to any particular section and was not asked to work on any on-going projects. His contact person was a Senior Policy Analyst in charge of a group of in-house researchers. The initial aim was to gain information on language policy in Europe or case studies where translation was relevant.

The researcher was thus able to pursue his own research, although he was willing to perform other tasks as required. He proofread a number of papers for OSE, but nothing more.

OSE did not find the researcher's project especially pertinent to their concerns; translation was not an issue they considered central to their work. When the researcher wrote a paper on the role of translation in pan-European healthcare, they considered publishing it on their website but in the end decided not to.

OSE did not provide any training in research techniques as such, although some guidance was given on how to plan the healthcare article. The staff did not show the researcher the projects they were working on, simply because they were on different topics. Confidentiality issues thus never arose.

The researcher felt he was welcome at OSE, even though they initially seem not to have understood the aims of his placement. After a meeting with several key researchers and having a one-on-one interview with the Senior Policy Analyst, people understood why he was there. He was invited to participate in the collective activities, including lunchtime sessions where key policymakers were invited as speakers. During the placement, he was given specific feedback on what he wrote.

The cost of the placement to the OSE was basically the energy consumed by his own laptop and occasional printing, as well as the work-hours spent by staff in the interviews and discussions. The researcher was there for 2 or 3 days per week and had access to a shared office. The cost is estimated to be below the 600 euros per month the OSE received.

It is highly doubtful that the OSE obtained any benefit from the placement in intellectual terms. There were no further contacts following the placement and, except for on-going feedback from the Senior Policy Analyst, no particular gains to the researcher in terms of knowledge, data-gathering, or insight into the industry. The researcher describes the placement as being not unenjoyable, although it could have lasted one month rather than three.

In this case, perhaps paradoxically, a host that was almost entirely dedicated to producing research was of little actual help in advancing the researcher's project. 


\section{Case study F: European Centre for Minority Issues (ECMI), Flensburg, Germany}

The search for a host institution in the field of language rights was necessarily based on contacting people with whom no prior networking had been established. This was a long and difficult process, as noted above. The ECMI was initially approached because their concern with multilingualism was mentioned in the researcher's readings, not because of any personal networking. In this case, a cold contact with the head of the ECMI Secretariat led to positive results.

The ECMI is a policy and research institute that plays an active advisory role for governments and organizations, particularly in eastern Europe. It has a team of fourteen employees plus five consultants. Their research focuses on minority-majority relations throughout Europe, dealing with issues such as citizenship, cultural diversity, governance, and security. The researcher was assigned to the Culture and Diversity Cluster, whose focus includes multilingualism in society.

The placement was over three months in 2013, with the researcher living in Flensburg and going to the ECMI every day. This came at a stage when he had already gathered most of the data for his own research project. He was seeking help with making sense of the information, particularly with respect to the integration of linguistic minorities. He received input in this issue and was able to draft the corresponding chapter of his dissertation. He was not looking at how translation was used within the ECMI. He was not asked to carry out any specific research tasks for the ECMI itself, and he was not given any training on research techniques. He did, however, interview their researchers, looking for insights on conceptual issues (for example, the meaning of "integration" as applied to linguistic minorities) rather than research techniques as such.

On the first day of the placement, the researcher gave a presentation on his project, and all ECMI staff were invited. The lecture was followed by a discussion of how the ECMI could help him further his research. He was also invited to participate in a conference, a workshop, and the lectures organized by the ECMI. His contact person read what he wrote and gave feedback, and the librarian gave him a tour of their on-site library and access to a number of online libraries and databases. Confidentiality was never an issue.

The costs to the ECMI included the use of an office, including a computer and printing, and the few work-hours spent interacting with the researcher. The ECMI did not request payment in exchange for hosting the researcher.

The benefits to the institution were mainly on the conceptual level, since they had previously not considered the role of translation in terms of minority-majority relations. The ECMI's Director found that translation should be more closely considered in terms of governance. Reporting on the visiting researcher, she wrote, "As a consequence of his stay and work, we will now include some of his specific focus area into our research cluster on language issues."

There have been follow-up exchanges since the placement. The researcher was invited to submit his work for publication as one of the ECMI papers, and the ECMI director attended his talk at an academic conference on language policy. It is felt that some of the contacts could be useful in the researcher's future job search, and that the ECMI's name in his curriculum will carry weight in the language-rights community. 
Subproject 4: Transformation through translation: media representation of political discourse in Europe

In this subproject, the researcher was a native speaker of Dutch with a strong command of English and French, and a basic command of Spanish. She held a degree in Germanic Literature and Linguistics, and a Masters in Translation. Her doctoral project focused on the representation of Amnesty International's (Amnesty) human rights discourse in various European sections of Amnesty. Although Amnesty is not a political institution as such, as a worldwide human rights NGO it pressures governments to take action against human-rights abuses. An important part of the research focused on the translation of press releases at various offices, and how translation work at Amnesty is organized in these offices. The research looked into how perceptions on the status of translation and translators influence the actual translation work and how it influences the way in which Amnesty is represented throughout Europe.

This subproject involved two placements, one with the OSE in Brussels, the other with Amnesty in Antwerp, Madrid and Paris. The first was not highly successful, the second was.

\section{Case study G: European Social Observatory (OSE), Brussels, Belgium}

The OSE, the partner in Case Study E above, was also selected as a host organization for subproject 4 . As the center has a large network of contacts within political institutions, it seemed to be a good match for a subproject focused on political discourse.

The researcher was there for a little less than a month, in September 2012, and interacted with the director only. The initial aim was for the researcher to translate the OSE English/French website into Dutch and to assist with translation tasks in the office. In effect, the arrangement was a close match with the OSE's initial request for intern translators, as described in Case Study E. This placement actually followed the one described in Case Study E, so the OSE was certainly aware that it was supposed to concern research rather than free translations, but to little avail. The researcher also aimed to learn how the organization worked, basically by attending some lunch seminars. As such, this would differ little from a placement for a trainee translator, although it was hoped that the director would provide further contacts that would be of use for research purposes. The initial planning was vague, however, and it turned out that the OSE's activities had little relation with translations of political discourse, let alone research on translation. The placement was thus reduced from three months to one.

The researcher was assigned a desk and was asked to bring a laptop - all direct and indirect costs were thus covered by the TIME project allocation of 600 euros a month - but any actual benefits could have been achieved by working online from home.

The one practical goal was the translation of the website, but that project failed because the OSE staff disagreed among themselves about the site's purpose and audience, particularly with respect to the roles of the French and Dutch languages. Ironically, policy conflict within the organization meant that they did not get the website translation that they initially came looking for. 
Although the institution has prestige and their name will no doubt enhance the researcher's curriculum, further interaction is unlikely.

\section{Case Study H: Amnesty International}

The placement with Amnesty was actually at three different centers over a period of five months in 2012 and 2013: at Amnesty Flanders in Antwerp and then at two offices of the Language Resource Center, in Madrid and Paris. The first contact was with the Antwerp office, which led to the contact in Madrid, which in turn led to the placement in Paris. Once you have a foot in certain doors, other doors open up.

Amnesty is a worldwide human-rights organization with offices in more than 80 countries. The regional office in Antwerp has about 20 employees (and many volunteers), none of whom are translators. Here the researcher joined the Urgent Actions team. The office in Madrid has some ten people in-house, of whom four are translators. It functions as the head of the Language Resource Center, which is a network of contacts in various Amnesty offices that work on language services, offering support with translation, interpreting, and terminology. The French translation service in Paris is a part of this network: it employs about ten people in-house, of whom six are translators. In Madrid and Paris, the researcher was not part of any particular team.

The initial aim of the Amnesty placements was to observe how translation fitted into the general workflows. The researcher had access to relevant documents and translations, and could interview members of staff. In Antwerp, the researcher carried out translation tasks for the Urgent Actions team, particularly with respect to their work with volunteer translators. In addition to helping out with actual translation work, this entailed analysis of existing translations and interviewing members of staff on their views about how Urgent Action translations were organized. Problems and possibilities for improving the organization of translation work were thus identified. The researcher also compared originals and translations in order to identify typical translation problems and issues for English to Dutch translation of Urgent Actions. On the basis of these findings, she developed a brochure with tips and advice for translators. The brochure has been made available on the website of the Antwerp office, as has a webpage with specific information for volunteer translators.

In Madrid and Paris, on the other hand, the researcher's main tasks were to help collect data on translation services at various Amnesty sections, and to assist with translation-memory alignment projects. She aligned one major Amnesty publication so that it could be added to the translation memory and to enable terminology to be extracted for the term database. In all, about half the researcher's time was spent on tasks set by the various offices, while the other half was spent collecting data for her own research. For this purpose, she observed staff members going about their daily tasks, carried out numerous interviews, and collected documents on Amnesty's translation policy and strategy. There was some overlap between these two facets. For example, the researcher designed a questionnaire so that the Language Resource Centre could take stock of how various sections were dealing with translation, as translation for many languages is organized on the local section level and working methods are hardly ever shared. The data collected were directly useful for her own research. In completing this task, she had access to Amnesty's previous questionnaires and the data obtained from 
them, and she received feedback on her own questionnaire, which is an invaluable learning experience (especially since she had never designed a questionnaire previously).

This is a case where the host institution is directly engaged in translation and is itself carrying out research on translation. The Language Resource Centre seems not to have concealed any research from the researcher, although confidentiality was an issue. A consent form was signed stating that names of members of staff would not be revealed in any reports or presentations, unless they explicitly agreed to share the information. The form also specified that the researcher was the only person who had access to the data that the institution collected and that was not in the public domain. The researcher was asked to keep any particular documents confidential.

While at the Amnesty offices, the researcher was assigned a desk with a computer. Her talks or interviews with members of staff ranged from 30 minutes to one hour, and there were additional meetings with staff about the work the researcher was doing for them. No money was paid to Amnesty for the desk or the time spent in the meetings, since the institution felt it could adequately benefit from the researcher's work on their projects and translation problems.

Relations with the Amnesty offices were difficult at first, since the nature and purpose of the placement was not well understood. However, once it was agreed that the researcher would work on relations with volunteer translators at the Antwerp office, the potential benefit became clear and relations were cooperative. The researcher gave two presentations at the office in Antwerp on her work, one at the beginning of her placement there and the other after her stay in Madrid, when she returned one week to the Antwerp office to share her experiences. She also learned about Amnesty by attending a presentation designed for new volunteers and interns. In Madrid and Paris, staff learned about her research project on a one-on-one basis. Prior to her arrival, an e-mail was sent to all staff members with basic information about the project. This information was then discussed in more detail on a one-on-one basis before each interview. For this kind of interaction, the researcher's physical presence was essential.

In sum, all three stays with Amnesty were useful for the researcher. She was able to learn about how translation works at an international organization and she collected considerable data. At the same time, all signs indicate that the placements were also beneficial for Amnesty, particularly because the research on volunteer translators was something that the Antwerp office considered important but had not had time to work on themselves. There have been follow-ups since the actual placements: the researcher gave a successful workshop for volunteer translators at the Antwerp office in October 2013, and she has been put in touch with Amnesty's head office in London. Further contact has been maintained with the Language Resource Centre. Both the Madrid and Paris offices have asked to be informed of further developments in the researcher's research and activities. The Madrid office asked explicitly that official feedback on the workshop for volunteer translators at the Antwerp office be shared with them, so that they can also learn from the researcher's activities. The placements were thus not only useful experiences in themselves but have also opened up a network of contacts, at the same time as they add prestige to the researcher's curriculum. The placements might enhance the researcher's chances of obtaining a job outside of the university system. 


\section{Lessons learned}

As noted above, previous research found that university-industry cooperation can flounder because of failures of communication, weak or unclear policy signals, and conflicting agendas (Technopolis 2011: 12). Examples of all those shortcomings are not hard to find in our case studies, especially with respect to communication skills and "unclear policy signals." In hindsight, it is easy to say that the research program itself could have done much more to explain the nature and aims of the placements, perhaps on a website available to both researchers and potential host organizations. Such explanation should have given precedents, examples, and illustrations of potential benefits for the hosts, especially in terms of long-term planning and improved workflow efficiencies. The big hurdle is to convince nonacademic partners that university researchers can contribute to solve their "real-world" problems. All that is easy to say after the fact. As it happened, we were mostly feeling our way through, without any well-established model, as indeed were most of the host organizations.

If we work inductively from the above cases studies, five of the placements were clear successes in terms of the projects initial aims (A, C, D, F, and H); two were clear failures $(\mathrm{E} / \mathrm{G}$, at the same host organization), and one gave mixed results (B was probably more of a failure in terms of two of the project's goals, but successful in terms of ongoing cooperation). Now, which factors are common to the successful cases, and which are shared by the less-than-wholly-successful ones?

At the risk of stating the obvious, the following three criteria seem to have played key roles: ${ }^{2}$

\section{All partners understand the basic arrangements of the placement and establish mutual} trust: When this did not happen (Cases E and G, where the nonacademic partner kept looking for free translations), the placement did not produce benefits. In cases where the host organization took some time to understand the arrangement and came to know the researcher more personally (Cases $\mathrm{C}, \mathrm{D}$, and $\mathrm{H}$ ), the dynamic of the placement improved considerably.

2. All partners see they can achieve some benefit from the placement: In cases where the host organization had no deep relation with the object of research (here translation), the placement could be cordial enough but did not transcend the level of altruism (Cases E/G scarcely approached altruism). In the negotiation processes that did not lead to a placement, the initial ideas proved to be too broad and abstract for the potential partner to perceive real benefits for themselves. In cases $\mathrm{C}, \mathrm{F}$ and $\mathrm{H}$, the possible benefits became clear in the course of the placement itself.

3. The host organization has in place some standing arrangements for welcoming visiting researchers: In cases where the host organization has procedures for dealing with visiting researchers (Cases $\mathrm{B}$ and $\mathrm{F}$ ), the placement fits into a pattern and is made relatively easy. The procedure at the ECMI included a vetting process (they asked to see

\footnotetext{
${ }^{2}$ A possible fourth criterion would be the size of the host organization, since it proved easier to attract the interest of smaller organizations. This may be because decision-making processes that involve fewer people are necessarily simpler, or because the smaller hosts cannot afford to invest in research on their own. However, since only three of the eight placements concern smaller organizations, we hesitate to propose this as a general principle.
} 
a research proposal prior to accepting the researcher), and the most cooperative arrangements included something similar on the side of the researcher (several potential hosts were discarded in the cases of the localization and audiovisual companies mentioned above).

In a sense, all these factors merely repeat the importance of clear communication of policy. They also tend to reinforce each other: if there are standing arrangements, then mutual benefits are likely to be perceived and the arrangements are likely to be understood and trusted. At the same time, when the nonacademic partner has no mechanism for receiving researchers, the placement can still be a success if the other two criteria are fulfilled (Cases A, C, D, and H). And then, we have one case (B) where there were indeed prior arrangements but it was difficult to perceive mutual benefits. The only criterion that is truly sine qua non seems to be number 1: the basic arrangements must be understood and trusted.

At the same time, we must ask if understanding and trust can in themselves constitute complete success. The pertinent goals of the TIME project (given above) were expressed with the empty bureaucratic phrases "to increase involvement," "to raise awareness," and "to establish foundations," all of which might indeed be achieved through understanding and trust. At the same time, those goals only really concern a first stage of success: that of a successful negotiation, getting a foot in the door, then occupying a temporary seat at the table. That "negotiation success" is not the same thing as a placement actually aiding in the completion of a research project (all five researchers had at least one positive experience in this regard), which again is not the same thing as what we might call "sustainable success," where interactions are not just set up but continue by themselves well after the subsidized project has finished, such that academic research has a permanent seat at the nonacademic tables. "Sustainability" was mentioned within the first of the TIME aims, and was of course a key term in the Lisbon Strategy of 2000 , but it is very difficult to attain. Our three criteria help us complete successful negotiations, but they cannot yet claim to success in terms of sustainability.

It is important to stress that these three criteria are not evaluations of the nonacademic partners. A failure in communication is a failure on both sides, and in many cases the prime failing was on the academic side, at the moment when prospective nonacademic partners were identified, sometimes without adequate attention being paid to potential incompatibilities.

Such would be the findings of a bottom-up analysis. Yet more can be said if we approach the problem top-down, from a model of multilevel social exchanges.

\section{Conclusion: A non-financial basis for cooperation?}

Previous studies, particularly from the United States (cf. Pertuzé et al. 2012), lament that many exchanges between university and industry lead to initial transfers of results but not to long-term economic impact. The University of California, for example, has an Industry-University Collaboration Program that is squarely focused on commercialization: if your project will not lead to financial benefits, it is not likely to attract industry. ${ }^{3}$ Judged in these terms, our eight case studies would all be deemed

\footnotetext{
${ }^{3} \mathrm{http}: / /$ www.ucop.edu/research-grants-program/programs/industry-university-collaboration-and-innovation/
} 
failures, since none of them was even conceptualized with a specific commercial aim in mind. There are, however, other ways of measuring success.

The French sociologist Pierre Bourdieu (e.g. 1972/1977) proposed that there are at least four kinds of capital that can be accumulated and exchanged: economic (money), cultural (knowledge), social (personal contacts), and symbolic (prestige). This plurality of capital might have functioned in our case studies in the following ways:

Cultural capital: Although the actual information gained through the placements would generally appear to be rather slight in terms of declarative knowledge ("knowing that..."), the gain in communication and career-development skills is generally positive from the perspective of the researchers. We have little evidence that any such skills or aptitudes were developed on the side of the host organizations, although the ECMI did indicate that its eyes had been opened to the importance of translation as an issue of minority rights.

Symbolic capital: As can be seen in the above case studies, all the placements resulted in a mutual if asymmetric exchange of prestige: the placement in itself was a positive element in the researcher's curriculum, and the fact of being associated with the university system, particularly with a European project, was generally considered a positive value by the host organizations. In Case Study $\mathrm{C}$ this prestige might have been partly converted into financial capital when the company was awarded a contract from the? Spanish national television.

Social capital: The need for networking was also evident in the setting up of some of the placements themselves ("negotiation success"), where prior contacts were of significant help (Cases A, B, and D). Further, in some of the Case Studies (A, B, D, F, and possibly $\mathrm{C}$ and $\mathrm{H}$ ) the social exchanges continued after the actual placement, building the kind of networks that not only should allow career advancement by the researchers but could also promote the development of joint projects in the future. This was approaching success in terms of sustainability. We thus find that excellent on-going cooperation can be achieved despite the absence of prior contacts (Cases C, D, F, and H), and that prior contacts may not lead to significant cooperation (the translation companies contacted prior to Cases $\mathrm{A}$ and $\mathrm{B}$, and Cases E and G). Personal contacts thus do not constitute a sufficient or necessary condition, and the exchange of social capital would appear to be less important than the general disposition of the host organization to welcome visiting researchers.

Of course, the prime cultural capital should be the lessons learned for future attempts to organize academic-nonacademic cooperation in the humanities. And the major conversion into economic capital will be when the researchers gain full-time employment, within or outside the academy. On that ultimate test of the project, we hope to report in the future.

\section{References}

Borrell-Damian, Lidia. 2009. Collaborative Doctoral Education. University-Industry Partnerships for Enhancing Knowledge Exchange. DOC-CAREERS Project. 
Brussels: European University Association. http://www.eua.be/eua-work-and-policyarea/research-and-innovation/doctoral-education/doc-careers/

Bourdieu, Pierre. 1972/1977. Outline of a Theory of Practice. Trans. Richard Nice. New York: Cambridge University Press.

Davey, Todd, et al. 2011. The State of European University-Business Cooperation. Münster: Science-to-Business Marketing Research Centre, Münster University of Applied Sciences. http://ec.europa.eu/education/highereducation/doc/studies/munster_en.pdf

European Council. 2000. "Presidency Conclusions". Lisbon European Council 23 and 24 March 2000. http://www.europarl.europa.eu/summits/lis1_en.htm. Accessed November 2013.

Lind, Frida, Alexander Styhre, and Lise Aaboen. 2013. "Exploring university-industry collaboration in research centres". European Journal of Innovation Management 16/1: 70-91.

Pertuzé, Julio, Edward S. Calder, Edward M. Greitzer, and William A. Lucas. 2010. "Best practices for industry-university collaboration". MIT Sloan Management Review 51/4: 83-90. http://sloanreview.mit.edu/article/best-practices-for-industryuniversity-collaboration/. Accessed November 2013.

Science Business Innovation Board AISBL. 2012. Making industry-university partnerships work. Lessons from successful innovations. http://www.sciencebusiness.net/Assets/94fe6d15-5432-4cf9-a656633248e63541.pdf

Technopolis Group. 2011. University Business Cooperation, 15 Institutional Case Studies on the Links between Higher Education Institutions and Business. http://ec.europa.eu/education/higher-education/doc/studies/technopolis_en.pdf.

TIME. 2011. "Problem statement and objectives". Translation Research Training: An integrated and intersectoral model for Europe (TIME- ITN 2010- 263954). http://eu-researchprojects.eu/time/Statement-objectives. Accessed November 2013. 